\title{
Conducted EMI causing Error Readings of Static Electricity Meters
}

\author{
G. Rietveld", D. Hoogenboom, and M. Acanski \\ VSL, Thijsseweg 11, Delft, The Netherlands; 'gert.rietveld@vsl.nl
}

\begin{abstract}
Following initial studies showing that conducted electromagnetic interference (EMI) can lead to large error readings of static electricity meters, VSL performed a thorough verification study confirming that wideband currents produced by non-linear, fast-switching loads indeed can lead to significant error readings of static meters. Key parameters of the EMI causing the errors are a short rise time and large peak height of the current step. When dimming linear or non-linear loads such as heaters and energy-saving lamps, the (lack of) internal filter in the dimmer has a large influence on these key parameters.

Index Terms - Electromagnetic compatibility, EMI, energy measurement, interference, revenue metering, standards, smart meter, static meter, watthour meters, wideband current.
\end{abstract}

\section{INTRODUCTION}

The increased use of power electronics in household appliances results in a rise of unwanted signals in the electricity network. It thus becomes more important to determine to what extent household equipment and energy meters are sensitive to this 'network pollution'. In a recent paper [1], prof. Leferink of the Twente University of Technology (UTwente) presented the results of a study on the effects of 'current pollution' on the energy reading of static electricity meters. In this study, heaters, non-dimmable energy-saving lamps and LED-lamps, both with and without an additional dimmer, were used to generate the electromagnetic interference (EMI) signals. Under the applied test conditions, several static meters showed deviations in their energy readings, with up to six times more energy consumption registered under the most extreme test conditions [1].

Immediately following the first findings of prof. Leferink in 2015 , VSL has verified that the disturbing signals used in the UTwente study indeed can lead to erroneous energy readings of static electricity meters. Subsequently, a large series of static meters were evaluated using a variety of EMI signals. This paper discusses the nature of the EMI signals resulting in static meter error readings together with some test results.

\section{TEST SETUP}

The VSL setup for testing EMI effects of wideband currents on the energy readings of static electricity meters is given in Fig. 1. It essentially is a set of loads connected to a power supply generating a $230 \mathrm{~V}, 50 \mathrm{~Hz}$ mains voltage, with a series of static electricity meters measuring the energy consumption of the loads. The actual energy consumption of the loads is determined with a wideband reference meter, consisting of a digitizer [2] together with a wideband shunt [3] and voltage divider. This instrument is also used to record the voltage and current waveforms of the applied EMI signals at $1 \mathrm{MSa} / \mathrm{s}$ sampling frequency. The uncertainty of the wideband reference meter is estimated to be better than $0.5 \%$ for all EMI signals used in the study. For undistorted $50 \mathrm{~Hz}$ voltage and current signals, the uncertainty is better than $0.02 \%$.

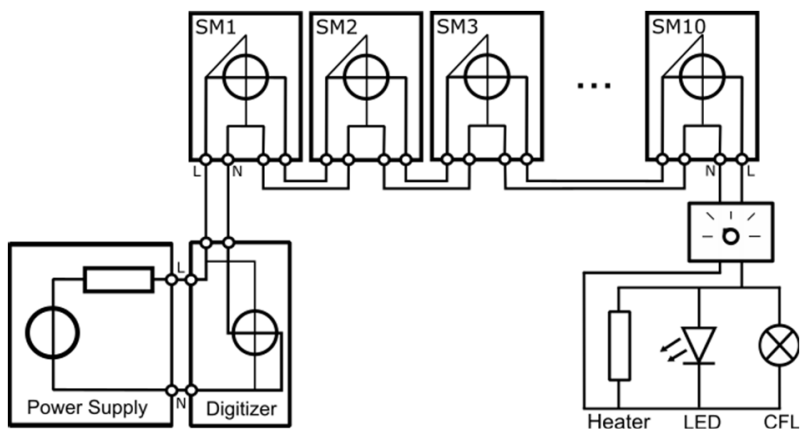

Fig. 1. Schematic of the VSL setup for determining the effects of conducted EMI caused by non-linear loads on the energy readings of static electricity meters.

The loads used in the VSL verification study to generate EMI are similar to those used in the initial UTwente study [1]. They consist of heaters as linear loads, and both energy-saving lamps (CFLs) and LED-lamps as non-linear loads. These loads were successively or jointly connected to the power supply to generate the different test signals, either with and without an additional dimmer. As an extension to the UTwente study [1], both dimmable and non-dimmable CFLs and LED-lamps were used. Furthermore, the effect of different filters in the dimmer was evaluated.

\section{EMI OF DIMMED LINEAR LOADS}

Fig. 2 gives the voltage and current wave shapes and current spectrum for a $1200 \mathrm{~W}$ heater in combination with the dimmer set at $135^{\circ}$. In the meter tests, the dimmer setting was varied between $0^{\circ}$ and $135^{\circ}$. Note that a $90^{\circ}$ phase-fired sine wave is part of present static meter testing in the EU [4]. However, where the EN 50470-3 standard limits the rise time to be at least $0.2 \mathrm{~ms}$, the rise time of the signal shown in Fig. 2 is less than $50 \mu$ s resulting in harmonics that extend up to many $\mathrm{kHz}$.

In our static meter tests, none of the more than 40 meters tested show error readings more than $5 \%$ for dimmer settings between $0^{\circ}$ and $90^{\circ}$. However, at $135^{\circ}$ some static meters start to deviate, with up to $60 \%$ higher energy readings. These meters all exploited Rogowski coils for their current measurement. The magnitude of the error reading strongly depends on the steepness of the current step. Varying the value of the filtering inductor inside the dimmer from $0 \mu \mathrm{H}$ to $250 \mu \mathrm{H}$, resulted in a variation of the error readings of a particular 
meter from less than $3 \%$ to $+46 \%$. Fig. 2 shows the wave shape at an inductance value of $27 \mu \mathrm{H}$, where the VSL test results best agreed with those of UTwente [1].
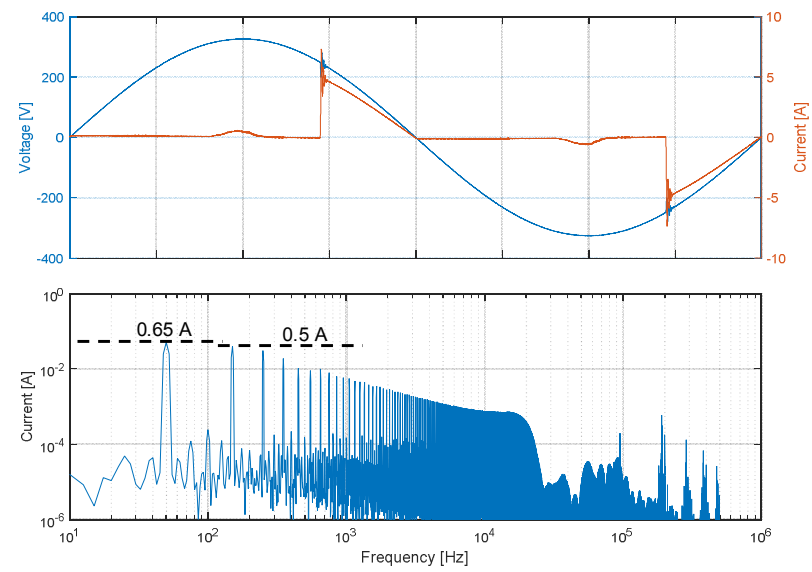

Fig. 2. Voltage and current waveforms (top) and current Fourier spectrum (bottom) of a heater controlled by a dimmer set at $135^{\circ}$.

\section{EMI OF DIMMED NON-LINEAR LOADS}

Fig. 3 gives the waveforms and current spectrum for one of the most severe EMI test signals used in this study, a $330 \mathrm{~W}$ load consisting of 30 energy-saving (CFL) lamps, in combination with the dimmer set at $135^{\circ}$. The already non-linear current of the non-dimmed CFL lamps under normal operating conditions becomes a highly-peaked wave shape when they are dimmed. Since the lamps are non-dimmable, they still consume $330 \mathrm{~W}$ at any dimmer setting (with minor to no variation in the light output), but the current wave shape is largely affected by the dimming. The maximum instantaneous current increases from $6 \mathrm{~A}$ under undimmed conditions, to $50 \mathrm{~A}$ with the dimmer set at $135^{\circ}$. In the Fourier spectrum, the non-dimmed CFL lamps show harmonics up to around $2 \mathrm{kHz}$, whereas when dimmed, the harmonics extend up to $20 \mathrm{kHz}$, with the components up to $1.5 \mathrm{kHz}$ having essential equal amplitude as the fundamental $(50 \mathrm{~Hz})$ signal.

Around half of the static meters tested showed error readings under the test signal of Fig. 3. Meters using Rogowski coils and Hall sensors to measure the current appeared to be most sensitive, as found by UTwente [1], but in our study also a few meters with shunt and current transformers showed error readings, up to $-40 \%$. For the latter types, the error reading might not be related to the current sensing technique but due to other inadequacies, e.g. in the metering chip.

For dimmable CFL lamps, the wave shapes and spectrum are similar to those of Fig. 2, with as main difference that the peak height is significantly reduced. With the dimmer set at $135^{\circ}$, both power and current peak value are around $25 \%$ of the values obtained for the non-dimmable lamps. Even these reduced test signals resulted in significant error readings, around half of those obtained for non-dimmable lamps.
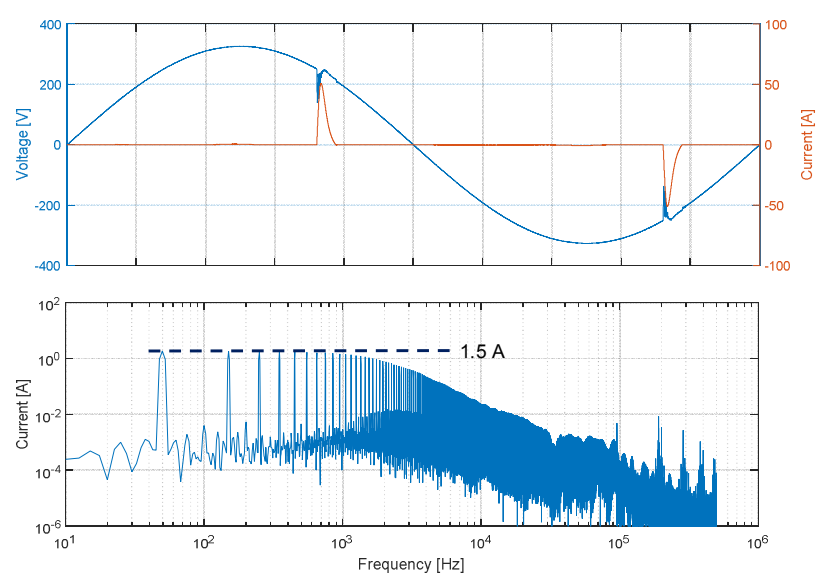

Fig. 3. Voltage and current waveforms (top) and current Fourier spectrum (bottom) of a set of 30 non-dimmable energy-saving lamps controlled by a dimmer set at $135^{\circ}$.

\section{CONCLUSION}

Fast, step-wise, changes in the current signal such as resulting from non-linear loads can lead to significant error readings of all types of present static electricity meters. Key parameters of the EMI causing such errors are fast rise times and high peak values. The test results show that details in the EMI signal considerably influence size and sometimes even sign of the error reading of the static meter.

Future research [5] should determine to what extent the test conditions used in the present laboratory studies actually occur in our electricity networks, and whether existing type approval standards for electricity meters [4] need amending.

\section{ACKNOWLEDGEMENT}

The research presented in this paper was funded by the Dutch utility association Netbeheer Nederland.

\section{REFERENCES}

[1] F. Leferink, C. Keyer, A. Melentjev, "Static Energy Meter Errors Caused by Conducted Electromagnetic Interference," IEEE Electromagnetic Compatibility Magazine, vol. 5, Issue 4, pp 49-55, Fourth Quarter 2016.

[2] G. Rietveld, C. Kramer, E. Houtzager, O. Kristensen, D. Zhao, C. de Leffe, and T. Lippert, "Characterisation of a wideband digitiser for power measurements up to $1 \mathrm{MHz}$ ", IEEE Trans. Instr. Meas., vol. 60, pp. 2195 - 2201 (2011).

[3] K. Lind, T. Srsdal, and H. Slinde, "Design, modeling, and verification of high-performance AC-DC current shunts from inexpensive components," IEEE Trans. Instr. Meas., vol. 57, no. 1, pp. 176-181, Jan. 2008.

[4] EN 50470-3, Electricity metering equipment (a.c.), Part 3: Particular requirements - Static meters for active energy (class indexes A, B, and C), 2006.

[5] P.S. Wright, G. Rietveld, F. Leferink, H.E. van den Brom, F.R.I Alonso, J.P. Braun, K. Ellingsberg, M. Pous and M. Svoboda, "Evaluation of EMI Effects on Static Electricity Meters," CPEM 2018 Conf. Digest, July 2018. 